\title{
Performance Analysis of Savonius Rotor Based Hydropower Generation Scheme with Electronic Load Controller
}

\author{
Rajen Pudur ${ }^{1}$ and Sarsing Gao ${ }^{2}$ \\ ${ }^{1}$ Electrical Engineering, National Institute of Technology, Yupia, Arunachal Pradesh 791112, India \\ ${ }^{2}$ Department of Electrical Engineering, North Eastern Regional Institute of Science and Technology (NERIST), Nirjuli, Arunachal \\ Pradesh 791 109, India \\ Correspondence should be addressed to Rajen Pudur; rajenpudur1977@gmail.com
}

Received 9 September 2015; Revised 11 December 2015; Accepted 5 January 2016

Academic Editor: Pallav Purohit

Copyright (C) 2016 R. Pudur and S. Gao. This is an open access article distributed under the Creative Commons Attribution License, which permits unrestricted use, distribution, and reproduction in any medium, provided the original work is properly cited.

\begin{abstract}
This paper describes the performance of electronic load controller (ELC) of asynchronous generator (AG) coupled to an uncontrolled Savonius turbine and variable water velocity. An AC-DC-AC converter with a dc link capacitor is employed to maintain the required frequency. The ELC which is feeding a resistive dump load is connected in parallel with the generating system and the power consumption is varied through the duty cycle of the chopper. Gate triggering of ELC is accomplished through sinusoidal pulse width modulation (SPWM) by sensing the load current. A MATLAB/Simulink model of Savonius rotor, asynchronous generator, ELC, and three-phase load is presented. The proposed scheme is tested under various load conditions under varying water velocities and the performances are observed to be satisfactory.
\end{abstract}

\section{Introduction}

Of late, distributed generation schemes are becoming popular in developed as well as developing countries to augment the existing power scenario. Induction generators are best suited for such applications due to their many advantages over other generators available [1]. The conventional sources of energy from coal, oil, natural gas, and uranium are observed to pollute air and water and produce ecological imbalances and, therefore, are hostile to both human beings and other plants and animals in the long run. Therefore, alternative sources of energy, like wind, solar, hydro, tidal, geothermal, and so forth, need to be explored to bring about a change in the energy scenario, in terms of both capacity and quality. Hydropower schemes generate a clean and environment friendly form of energy. However, large hydropower plants with generating capacity above $25 \mathrm{MW}$ are often considered to endow with drawbacks such as high initial cost and environmental impacts [2]. Therefore, distributed generation scheme with run-of-river scheme is considered to be a benign source of energy. The recent survey conducted by Energy Next (EN) in collaboration with the Ministry of New and Renewable Energy (MNRE), Govt. of India, in April
2015 reveals that the States of Arunachal Pradesh, Himachal Pradesh, and Uttarakhand alone have small hydropower (SHP) potential of $5447.16 \mathrm{MW}$ with harnessed capacity of 917.63 MW [3]. This figure may go up with installation of more run-of-river schemes in these areas. In smaller capacity hydropower plants, use of uncontrolled turbines is preferred, thus allowing the water flow as it comes and driving the turbine-generator set. Use of costly governors in such applications is unwise; thus use of load control mechanism is usually adopted. In this paper, a mechanism is evolved to regulate the consumer's load by diverting additional load to a dump load, thereby maintaining the power output of the machine by the use of an electronic load controller (ELC).

The use of ELC in the proposed scheme is realized by incorporating an AC-DC-AC converter similar to that of a wind energy conversion system, which produces a constant voltage and constant frequency from variable water velocity. Once a stable voltage and frequency are achieved, the total output power remains constant and hence the power switching between the main load and the dump load becomes feasible.

The turbine selected in the present study is a vertical axis Savonius rotor, which is commonly used as wind turbines 


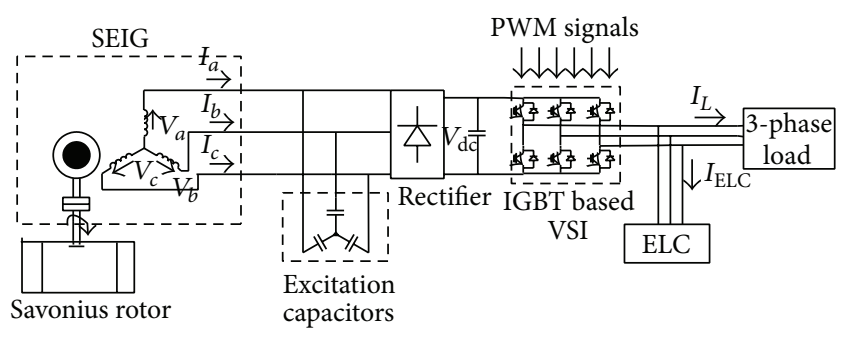

FIGURE 1: Schematic diagram of power generating scheme.
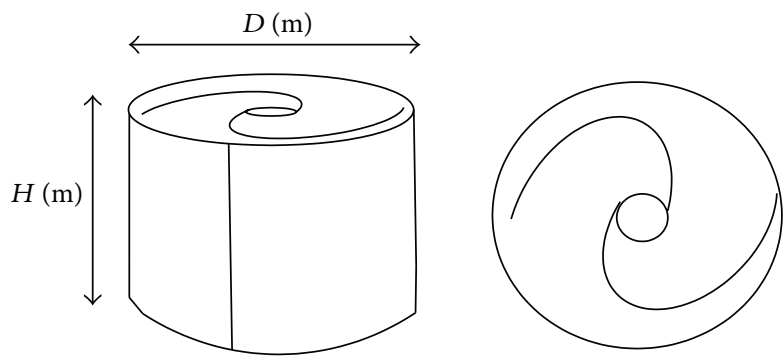

Figure 2: Savonius rotor.

$[4,5]$. It is a unique fluid mechanical device which works on drag effect mechanism rather than lift mechanism as in the case of the rest of the wind turbines. It is well proven that Savonius rotor can be effectively used for generating power using hydrodynamics in addition to aerodynamics principles [6]. It is a high solidity rotor. It is simple and easy to construct and can be implemented in any suitable locations [7, 8]. A typical Savonius rotor is shown in Figure 2. The drag coefficient of the concave surface is larger than the convex surface, thus forcing the rotor to rotate. It generates much higher starting torque compared to other vertical axis turbines [9]. This type of turbine is self-starting and provides high torque at low speeds. Implementation of ELC in conventional small scale hydropower generating schemes has been detailed in [10-13]. In these systems, reaction type of turbines which are ideally suited for low head hydropower plants is advocated.

The schematic diagram of the proposed scheme is shown in Figure 1.

\section{System Configuration}

In the proposed scheme, a Savonius rotor coupled with a $7.5 \mathrm{~kW}, 3$-phase, $415 \mathrm{~V}, 14.5 \mathrm{~A}, 50 \mathrm{~Hz}$, Y-connected, 4-pole, squirrel cage induction machine is employed. The excitation of the AG is achieved by means of a delta connected capacitor bank of $140 \mu \mathrm{F}$. The dimension of Savonius rotor so selected is given in the appendix.

The power output from Savonius turbine is given by

$$
P=0.5 C_{\mathrm{p}} A \rho V^{3},
$$

where $P$ is power output (W), $\rho$ is the density of water $\left(\mathrm{kg} / \mathrm{m}^{3}\right), A$ is the swept area of rotor $\left(\mathrm{m}^{2}\right), V$ is the velocity of water $(\mathrm{m} / \mathrm{s})$, and $C_{\mathrm{p}}$ is the power coefficient.
Tip speed ratio is given by

$$
\operatorname{TSR}=\frac{\omega D}{2 V},
$$

where $\omega$ is the angular velocity and $D$ is rotor diameter $(\mathrm{m})$. Coefficient of torque $\left(C_{t}\right)$ is given by

$$
C_{\mathrm{t}}=\frac{C_{\mathrm{p}}}{\mathrm{TSR}}
$$

Shaft torque $\left(T_{\text {sh }}\right)$ is given by

$$
T_{\mathrm{sh}}=\frac{P}{\omega}=\frac{0.5 C_{\mathrm{p}} A \rho V^{3}}{2 \pi N / 60} .
$$

The generated voltage and frequency of the machine are likely to vary with the varying velocity of river water. This, in turn, would result in unbalanced voltage and frequency at the load end. Thus, for uncontrolled turbine with varying input power, it is essential to determine the real and reactive power requirements of the generating machine in order to arrest the changes in terminal voltage and frequency. To maintain the rated voltage and frequency at the load end therefore, an ACDC-AC converter realized with the help of an uncontrolled rectifier and insulated gate bipolar transistor (IGBT) based current controlled voltage source inverter (CC-VSI) is used. The triggering pulses to the three-legged IGBTs are varied in accordance with the varying input power.

The variation in the DC link capacitor voltage presents the direct-axis component of current from the machine. The peak value of the line-to-line voltage from the machine is computed and compared with the reference peak value $(415 \sqrt{ } 2 \mathrm{~V})$. The difference between these two quantities is the reactive power required by the machine or is the amount of quadrature-axis component of current to be supplied to the machine. These two axes reference currents, namely, $I_{\mathrm{ds}}^{*}, I_{\mathrm{qs}}^{*}$, are converted into three-phase form by inverse Park's transformation [14]. The " $\cos (\omega t)$ " and " $\sin (\omega t)$ " terms needed for Park's transformation are derived with the help of a phase locked loop (PLL) which is fed with unit templates of line voltages from the machine. The three-phase reference currents thus obtained are compared with the actual load currents in a hysteresis current controller to yield the firing signals for the six devices in the voltage source inverter (VSI). The fluctuation in capacitance voltage is due to power consumed by the devices in the VSI and filter resistance.

2.1. Generation of Unit Voltage Templates. The line voltages $\left(V_{\mathrm{ab}}, V_{\mathrm{bc}}\right.$, and $\left.V_{\mathrm{ca}}\right)$ of the generator terminals are considered sinusoidal and therefore, their amplitudes are computed as

$$
V_{\text {tactual(peak) }}=\sqrt{\frac{2}{3}\left(V_{\mathrm{ab}}^{2}+V_{\mathrm{bc}}^{2}+V_{\mathrm{ca}}^{2}\right)} .
$$




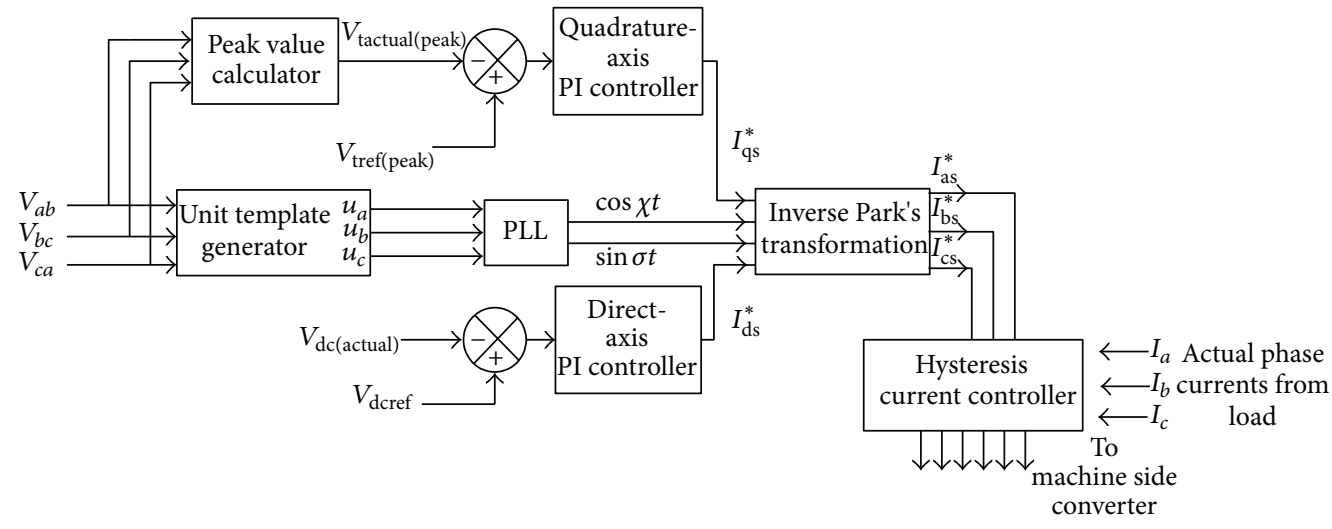

FIGURE 3: Schematic diagram of control scheme.

The unit template voltages are derived as

$$
\begin{aligned}
& u_{\mathrm{a}}=\frac{V_{\mathrm{ab}}}{V_{\text {tactual(peak) }}}, \\
& u_{\mathrm{b}}=\frac{V_{\mathrm{bc}}}{V_{\text {tactual(peak) }}}, \\
& u_{\mathrm{c}}=\frac{V_{\mathrm{ca}}}{V_{\text {tactual(peak) }}} .
\end{aligned}
$$

2.2. Quadrature-Axis Component of Reference Source Currents. The ac voltage error $V_{\operatorname{err}(n)}$ at the $n$th sampling instant is given by

$$
V_{\operatorname{err}(n)}=V_{\text {tref(peak })(n)}-V_{\text {tactual }(\text { peak })(n)},
$$

where $V_{\text {tref(peak)(n) }}$ is the peak value of the three-phase ac voltage being sensed at the generator terminal at the $n$th instant. The output of the PI controller $\left(I_{\mathrm{qs}(n)}^{*}\right)$ for maintaining the ac terminal voltage constant at the $n$th instant is expressed as

$$
I_{\mathrm{qs}(n)}^{*}=I_{\mathrm{qs}(n-1)}^{*}+K_{\mathrm{pa}}\left\{V_{\mathrm{err}(n)}-V_{\mathrm{err}(n-1)}\right\}+K_{\mathrm{ia}} V_{\mathrm{err}(n)},
$$

where $K_{\mathrm{pa}}$ and $K_{\mathrm{ia}}$ are the proportional and integral gain constants of the PI controller, $V_{\operatorname{err}(n)}$ and $V_{\operatorname{err}(n-1)}$ are voltage errors in the $n$th and $(n-1)$ th instants, and $I_{\mathrm{qs}(n-1)}^{*}$ is the amplitude of quadrature component of the reference source current at the $(n-1)$ th instant.

2.3. Direct-Axis Component of Reference Source Currents. The error in dc bus voltage $\left(V_{\mathrm{dcerr}(n)}\right)$ of the VSI at the $n$th sampling instant is given by

$$
V_{\mathrm{dcerr}(n)}=V_{\mathrm{dcref}(n)}-V_{\mathrm{dc}(\operatorname{actual})(n)},
$$

where $V_{\operatorname{dcref}(n)}$ is the reference dc voltage and $V_{\mathrm{dc}(\operatorname{actual})(n)}$ is the DC link voltage of the VSI being sensed at the $n$th instant. The output of the PI controller $\left(I_{\mathrm{ds}(n)}^{*}\right)$ for maintaining $\mathrm{dc}$ bus voltage at the $n$th instant is expressed as

$$
\begin{aligned}
I_{\mathrm{ds}(n)}^{*}= & I_{\mathrm{ds}(n-1)}^{*}+K_{\mathrm{pd}}\left\{V_{\mathrm{dcerr}(n)}-V_{\mathrm{dcerr}(n-1)}\right\} \\
& +K_{\mathrm{id}} V_{\mathrm{dcerr}(n)},
\end{aligned}
$$

where $I_{\mathrm{ds}(n)}^{*}$ is considered as the amplitude of active source current at the $n$th instant while $K_{\mathrm{pd}}$ and $K_{\mathrm{id}}$ are the proportional and integral gain constants of $\mathrm{dc}$ voltage PI controller.

2.4. Reference Source Currents. The reference source currents $\left(I_{\mathrm{as}}^{*}, I_{\mathrm{bs}}^{*}\right.$, and $\left.I_{\mathrm{cs}}^{*}\right)$ are obtained with the help of inverse Park's transformation as shown in

$$
\begin{aligned}
& I_{\mathrm{dq} 0}=T I_{\mathrm{abc}} \\
& =\sqrt{\frac{2}{3}}\left[\begin{array}{ccc}
\cos (\omega t) & \cos \left(\omega t-\frac{2 \pi}{3}\right) & \cos \left(\omega t+\frac{2 \pi}{3}\right) \\
\sin (\omega t) & \sin \left(\omega t-\frac{2 \pi}{3}\right) & \sin \left(\omega t+\frac{2 \pi}{3}\right) \\
\frac{\sqrt{2}}{2} & \frac{\sqrt{2}}{2} & \frac{\sqrt{2}}{2}
\end{array}\right]\left[\begin{array}{c}
I_{\mathrm{a}} \\
I_{\mathrm{b}} \\
I_{\mathrm{c}}
\end{array}\right] .
\end{aligned}
$$

2.5. Current Controller. The load currents $\left(I_{\mathrm{a}}, I_{\mathrm{b}}\right.$, and $\left.I_{\mathrm{c}}\right)$ are compared with the reference source currents $\left(I_{\mathrm{as}}^{*}, I_{\mathrm{bs}}^{*}\right.$, and $I_{\mathrm{cs}}^{*}$ ) and error signals are passed through hysteresis band to generate the firing pulses, which are operated to produce output voltage in manner to reduce the current error. Figure 3 shows the three-phase CC-VSI with hysteresis current controller.

The output of the current controller decides the switching patterns to be given to the IGBTs in the VSI. The current errors are computed as

$$
\begin{aligned}
& I_{\mathrm{aserr}}=I_{\mathrm{as}}^{*}-I_{\mathrm{a}}, \\
& I_{\mathrm{bserr}}=I_{\mathrm{bs}}^{*}-I_{\mathrm{b}}, \\
& I_{\mathrm{cserr}}=I_{\mathrm{cs}}^{*}-I_{\mathrm{c}} .
\end{aligned}
$$

\section{Design and Control of ELC}

Although the input power is varying, with the help of AC-DC-AC converter, the generator terminal voltage and frequency are observed to be constant. Thus, the total power generated remains constant, so a power diverter circuit such as an ELC may be connected in parallel to the main load. This circuit diverts the unused power to an auxiliary load or dump load thus helping in achieving balance of the power system. The ELC is designed using IGBT based chopper switch. 


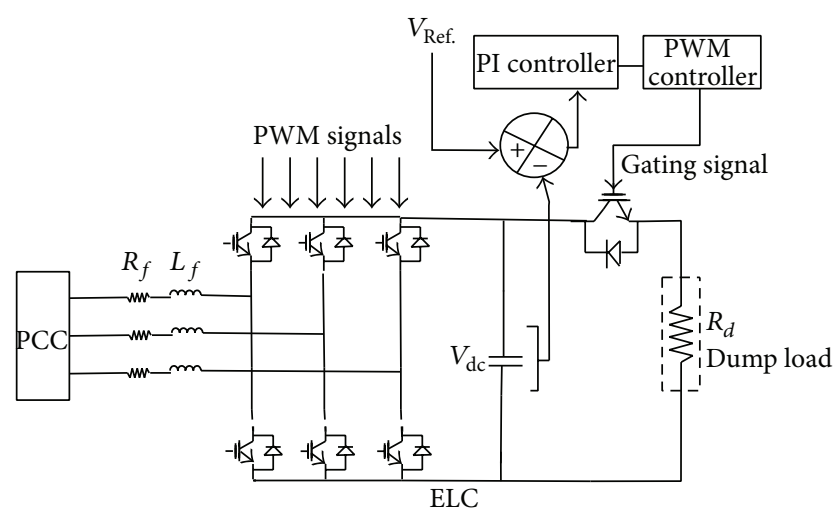

FIGURE 4: Schematic diagram of ELC and control scheme for chopper.
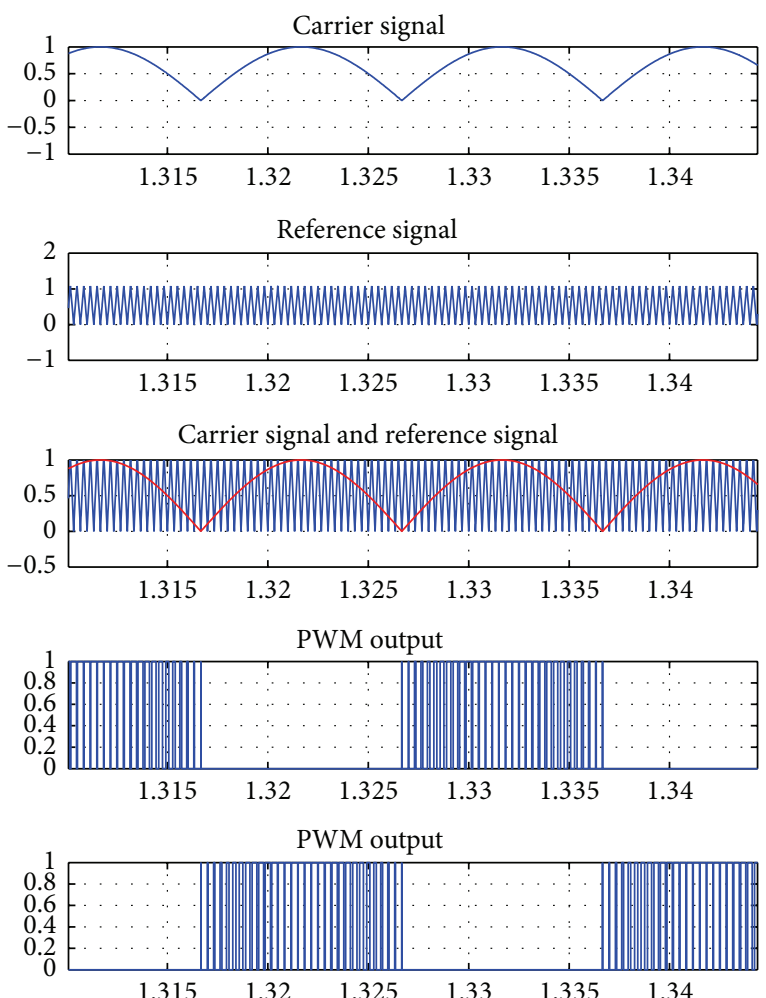

FIGURE 5: Output pulses from SPWM method.

Figure 4 shows the control scheme of ELC and chopper circuit. The ELC is connected to main circuit with point of common coupling (PCC). The three-phase load currents are compared with the reference carrier current generated with $4 \mathrm{kHz}$. The error signal is passed through sinusoidal pulse width modulation (SPWM), and pulses are then fed to IGBT of the voltage source inverter, as shown in Figure 5.

The rating of IGBT switches depends on the rated voltage and power of AG. The DC output voltage of VSI corresponding to rated voltage of $A G$ is given by

$$
V_{\mathrm{dc}}=\frac{V_{L} \times 3 \sqrt{2}}{\pi}=1.35 \times 415=560 \mathrm{~V},
$$

where $V_{L}$ is rms line voltage of AG.
For feeding reactive power in case of $0.8 \mathrm{pf}$ lagging reactive load it is found that AGs require $130 \%-160 \%$ of rated generated power [10-12]. Therefore, for $7.5 \mathrm{~kW}$ generators the VAR rating of the controller should be around $9.975 \mathrm{kVAR}$ (133\%).

Then, the apparent power $S$ is given by

$$
S=\sqrt{7.5^{2}+9.98^{2}}=12.48 \mathrm{kVA} \text {. }
$$

So the current rating of the converter is

$$
\begin{aligned}
3 V I_{\mathrm{c}} & =12.48, \\
I_{\mathrm{c}} & =17.36 \mathrm{~A} .
\end{aligned}
$$

Now, average current flowing through ELC can be taken as $90 \%$ of converter rms current, considering the worst case of load unbalancing:

$$
I_{\text {(average) }}=0.90 \times 17.36=15.62 \mathrm{~A} \text {. }
$$

Considering voltage ripple in $V_{\mathrm{dc}}$ in the order of $2 \%$ then

$$
V_{\mathrm{dc}(\text { ripple })}=2 \% \text { of } 560=11.2 \mathrm{~V} \text {. }
$$

Taking the values of $V_{\mathrm{dc}(\text { ripple) }}, I_{\text {(average) }}$, and $\omega=314 \mathrm{r} / \mathrm{s}$, we have

$$
C_{\mathrm{dc}}=\frac{I_{(\text {average })}}{\left(2 \omega V_{\mathrm{dc}}\right)}=2220.7 \mu \mathrm{F} \approx 3000 \mu \mathrm{F} .
$$

$3000 \mu \mathrm{F}$ is selected which is available in market.

Rating of dump load is

$$
R_{\mathrm{dp}}=\frac{V_{\mathrm{dc}}^{2}}{P_{R}}=\frac{560^{2}}{7500}=48 \Omega \approx 50 \Omega .
$$

Value of $R_{\mathrm{dp}}$ is selected as $50 \Omega$ for giving wide range of control to the controller, where $R_{\mathrm{dp}}$ is resistance of dump load and $P_{R}$ is rated power of generator.

The control signal for chopper is generated through the error signal generated by comparing voltage across DC capacitor and the reference voltage of $560 \mathrm{~V}$. Chopper regulations maintain the machine terminal voltage constant by feeding additional load to dump load.

The output power of the AG is held constant at varying consumer loads. Thus, the generated power is given by

$$
P_{\text {gen }}=P_{\text {ELC }}+P_{\text {Load }} \text {, }
$$

where $P_{\text {gen }}$ is generated power by the AG, $P_{\text {Load }}$ is consumer's load, and $P_{\text {ELC }}$ is the power absorbed by the ELC [13].

\section{Results and Discussion}

A complete hydropower generation scheme consisting of a Savonius rotor, asynchronous machine, and AC-DC-AC converter connected to three-phase load is modeled and simulated in MATLAB/Simulink environment. Varying water velocities ranging from $1.96 \mathrm{~m} / \mathrm{s}$ to $2.02 \mathrm{~m} / \mathrm{s}$ are considered. Table 1 shows the variation of active power with the velocity of water. 
TABLE 1: Variation of output power with velocity of water.

\begin{tabular}{lcc}
\hline S/number & Velocity of water $(\mathrm{m} / \mathrm{s})$ & Active power output $(\mathrm{kW})$ \\
\hline 1 & 1.0 & 0.5 \\
2 & 1.3 & 1.2 \\
3 & 1.8 & 1.35 \\
4 & 1.96 & 2.0 \\
5 & 2.0 & 2.5 \\
\hline
\end{tabular}
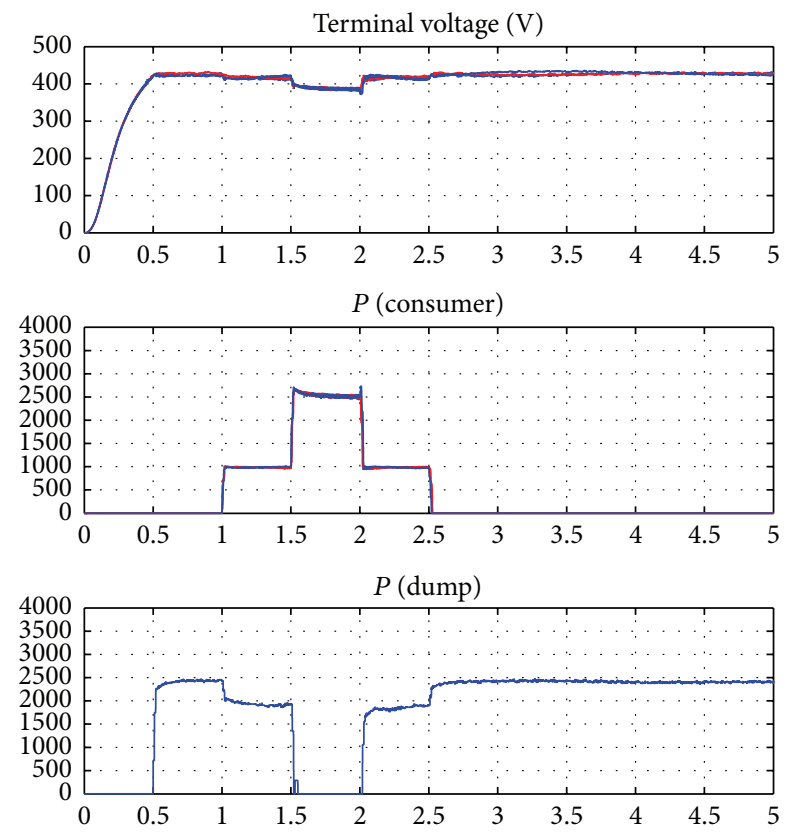

FIGURE 6: Variation of consumer power and dump load power.

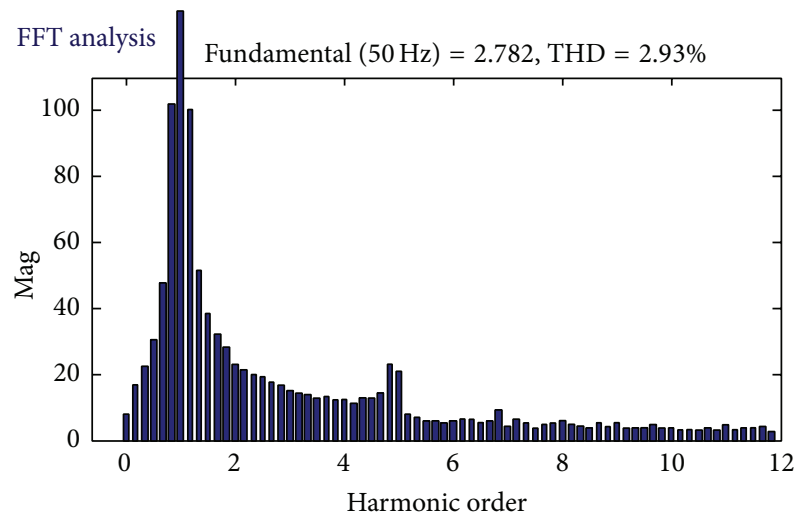

Figure 7: FFT analysis of load current at full load.

Three-phase resistive loads are switched in at different instants; three-phase loads of $1 \mathrm{~kW}, 2.5 \mathrm{~kW}$, and $1 \mathrm{~kW}$, respectively, are connected and then disconnected at $1.0 \mathrm{~s}$ and $1.5 \mathrm{~s}$, $1.5 \mathrm{~s}$ and $2.0 \mathrm{~s}$, and $2.5 \mathrm{~s}$ and $3.0 \mathrm{~s}$, respectively, as shown in Figure 6. As seen from the figure, the rated terminal voltage is maintained while the machine is loaded and there is a precise load sharing between the main load and the dump load. The generator is operated to produce a maximum power output of $2.5 \mathrm{~kW}$. When the consumer's load is zero, the dump load takes the total generated power. On the other hand,
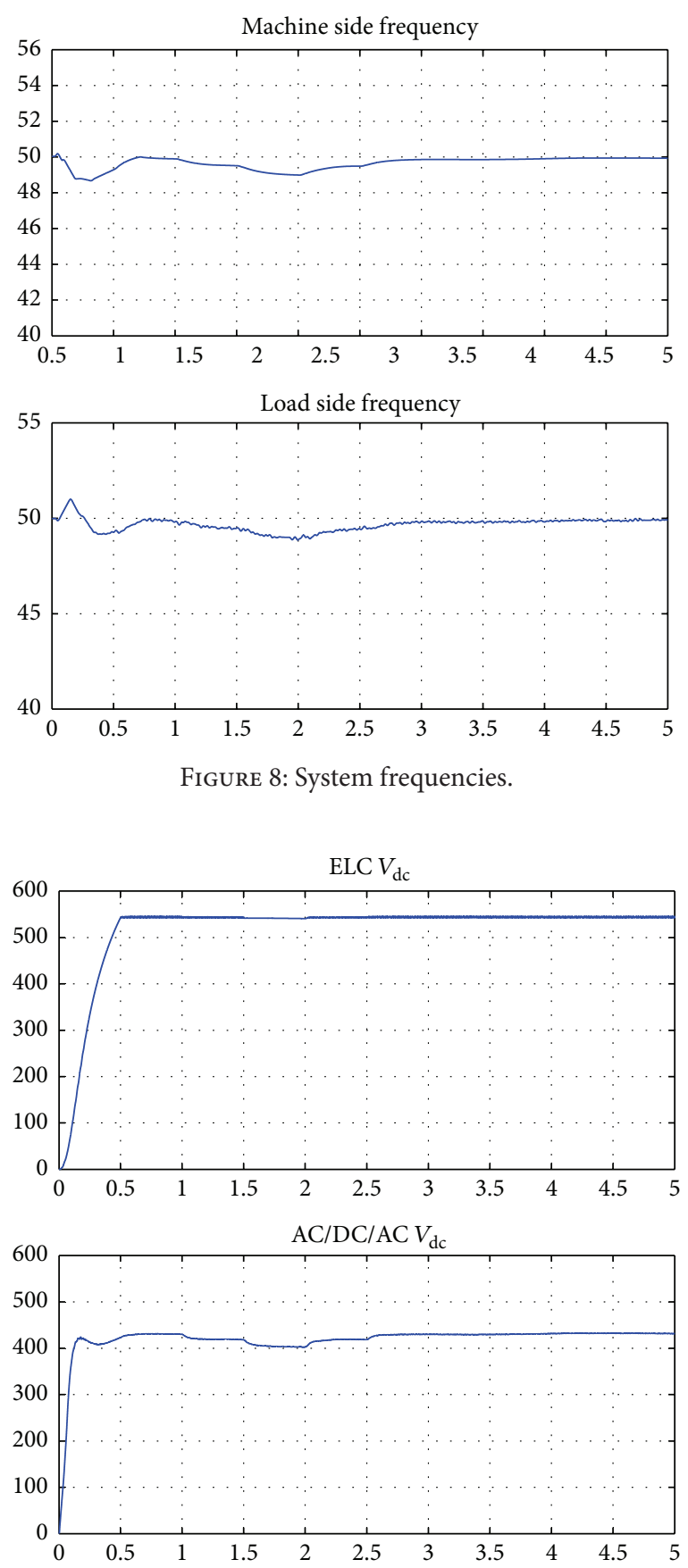

Figure 9: DC link voltage of AC-DC-AC converter and ELC.

when the consumer's load is equal to the maximum generator output, no power is diverted to dump load. This act of power switching between the two ensures a constant total power output from the machine at constant terminal voltage.

The Fast Fourier Transforms (FFT) analysis of load current at full load indicates a total harmonic distortion (THD) of $2.93 \%$. This is shown in Figure 7 . The ELC starts working at $0.5 \mathrm{~s}$ when the voltage across the DC link capacitor builds up to 560 volts. Figures 8 and 9 show the system frequencies and DC link voltages of AC-DC-AC converter and ELC while Figure 10 shows the MATLAB/Simulink model of the 


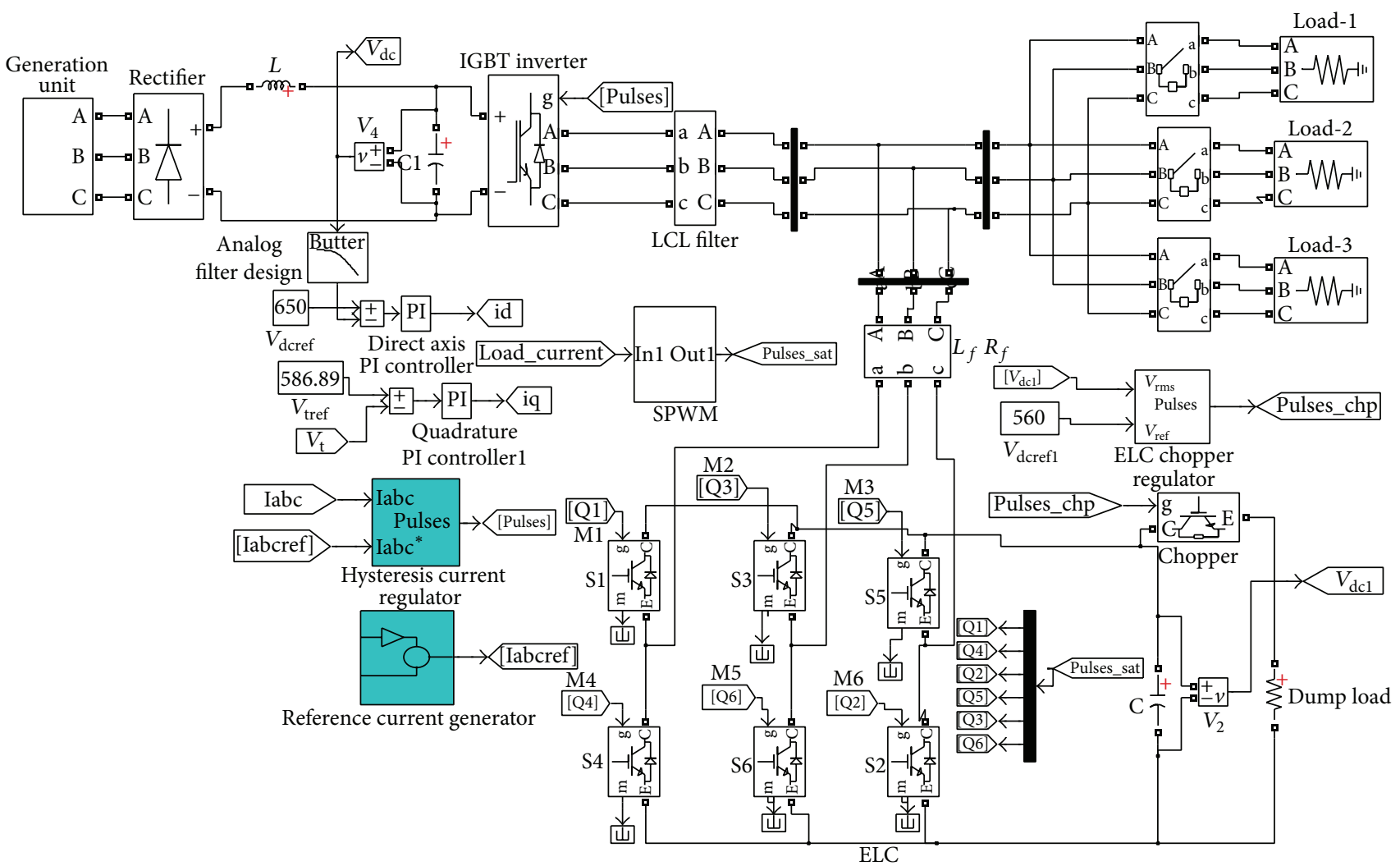

Figure 10: MATLAB model of AG-ELC system.

complete system. In this paper, variable water velocity is considered, as the analysis becomes easier when the input power remains constant, which means velocity of water remains the same, but in actual practice, it will never be constant; hence the use of dual converters plays a vital role here.

\section{Conclusions}

The work presented in this paper demonstrates a successful power switching between the main load and the dump load while maintaining a constant terminal voltage. The performance of ELC is satisfactory. The AC-DC-AC converter performs satisfactorily with independent control of active and reactive power thus giving a constant voltage and frequency output at the machine terminal. The proposed system may be adopted in rural areas where distributed power generation is a suitable option and the consumers are less. The power diverted to the dump load may also be gainfully utilized in battery charging and supplying power to some auxiliary circuit or equipment.

\section{Appendices}

\section{A. Machine Parameters}

Three-phase generating unit was as follows: $7.5 \mathrm{~kW}, 415 \mathrm{~V}$, $14.5 \mathrm{~A}, 50 \mathrm{~Hz}$, Y-connected, 4-pole, squirrel induction machine:

$$
\begin{aligned}
& R_{\mathrm{s}}=0.9 \Omega, R_{\mathrm{r}}=0.66 \Omega, X_{\mathrm{ls}}=X_{\mathrm{lr}}=1.437 \Omega, \text { and } \\
& X_{\mathrm{ml}}(\text { sat. })=35.74 \Omega .
\end{aligned}
$$

\section{B. Controller Parameters for AC/DC/AC Controller}

Consider $C_{\mathrm{dc}}=2000 \mu \mathrm{F}, K_{\mathrm{pa}}=0.0118, K_{\mathrm{ia}}=0.0018, K_{\mathrm{pd}}=$ 0.036 , and $K_{\text {id }}=0.0008$.

\section{Savonius Rotor Parameters}

The Savonius rotor parameters are as follows: $D_{\mathrm{r}}$ (rotor diameter) $=2 \mathrm{~m}, H_{\mathrm{r}}$ (rotor height) $=2 \mathrm{~m}, C_{\mathrm{p}}$ (power coefficient) $=0.25, \rho\left(\right.$ water density at $\left.25^{\circ} \mathrm{C}\right)=997.0479 \mathrm{~kg} / \mathrm{m}^{3}$, and inner diameter $=1.8 \mathrm{~m}$, with thickness $=100 \mathrm{~mm}$, no overlapping.

\section{LCL Filter Parameters}

Consider $L_{\mathrm{f}}=80 \mathrm{mH}, C_{\mathrm{f}}=40 \mu \mathrm{F}, R_{\mathrm{f}}=30 \Omega$.

\section{E. ELC Parameters}

The ELC parameters are as follows: current rating $=17.36 \mathrm{~A}$, DC capacitor rating (selected) $=3000 \mu \mathrm{F}$, rating of dump load $($ selected $)=50 \Omega$, controller parameter, $K_{\mathrm{p}}=0.5$, and $K_{\mathrm{i}}=8$. 


\section{Conflict of Interests}

The authors declare that there is no conflict of interests regarding the publication of this paper.

\section{References}

[1] Md. Orai, T. Ahmed, M. Nakaoka, and M. Z. Youssef, "Efficient performances of induction generator for wind energy utilization," in Proceedings of the 30th Annual Conference of IEEE Industrial Electronics Society, Busan, South Korea, November 2004.

[2] T. Abbasi and S. A. Abbasi, Renewable Energy Sources: Their Impact on Global Warming and Pollution, PHI Publication, 3rd edition, 2013.

[3] Energy Next, "Mission possible: potential and installed capacity," Monthly Magazine, Ministry of New and Renewable Energy (MNRE), Government of India, vol. 5, no. 6, pp. 14-21, 2015.

[4] S. Gao and R. Pudur, "Harnessing hydroelectric power using Savonius rotor coupled with asynchronous generator connected to grid," in Proceedings of the IEEE PES Asia-Pacific Power and Energy Engineering Conference (APPEEC '13), pp. 1-4, Kowloon, Hong Kong, December 2013.

[5] R. Pudur and S. Gao, "Savonius rotor based hydropower generation," in Proceedings of the International Symposium on Aspects of Mechanical Engineering \& Technology for Industry (AMETI '14), vol. 1, pp. 104-111, Itanagar, India, December 2014.

[6] M. N. I. Khan, T. Iqbal, M. Hinchey, and V. Masek, "Performance of savonius rotor as a water current turbine," The Journal of Ocean Technology, vol. 4, no. 2, pp. 71-83, 2009.

[7] U. K. Saha and M. Jaya Rajkumar, "On the performance analysis of Savonius rotor with twisted blades," Renewable Energy, vol. 31, no. 11, pp. 1776-1788, 2006.

[8] Md. Hadi Ali, "Experimental comparison study for Savonius wind turbine of two \& three blades at low wind speed," International Journal of Modern Engineering Research, vol. 3, no. 5, pp. 2978-2986, 2013.

[9] G. Kailash, T. I. Eldho, and S. V. Prabhu, "Performance study of modified savonius water turbine with two deflector plates," International Journal of Rotating Machinery, vol. 2012, Article ID 679247, 12 pages, 2012.

[10] B. Singh, G. K. Kasal, A. Chandra, and K.-A. Haddad, "Electronic load controller for a parallel operated isolated asynchronous generator feeding various loads," Journal of Electromagnetics Analysis and Applications, vol. 3, no. 4, pp. 101-114, 2011.

[11] B. Singh, G. K. Kasal, and S. Gairola, "Power quality improvement in conventional electronic load controller for an isolated power generation," IEEE Transactions on Energy Conversion, vol. 23, no. 3, pp. 764-773, 2008.

[12] B. Singh, S. S. Murthy, and S. Gupta, "Transient analysis of self-excited induction generator with electronic load controller (ELC) supplying static and dynamic loads," IEEE Transactions on Industry Applications, vol. 41, no. 5, pp. 1194-1204, 2005.

[13] S. Gao, G. Bhuvaneswari, S. S. Murthy, and U. Kalla, "Efficient voltage regulation scheme for three-phase self-excited induction generator feeding single-phase load in remote locations," IET Renewable Power Generation, vol. 8, no. 2, pp. 100-108, 2014.

[14] J. M. D. Murphy and F. G. Turnbull, Power Electronic Control of AC Motors, Pergamon Press, New York, NY, USA, 1990. 

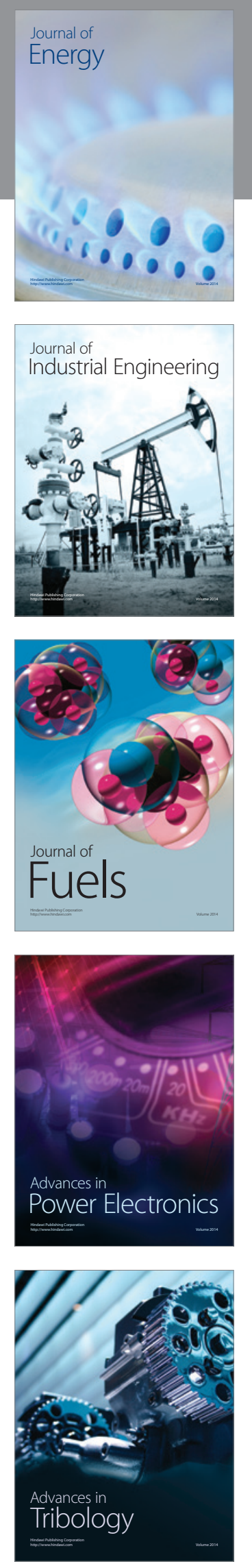
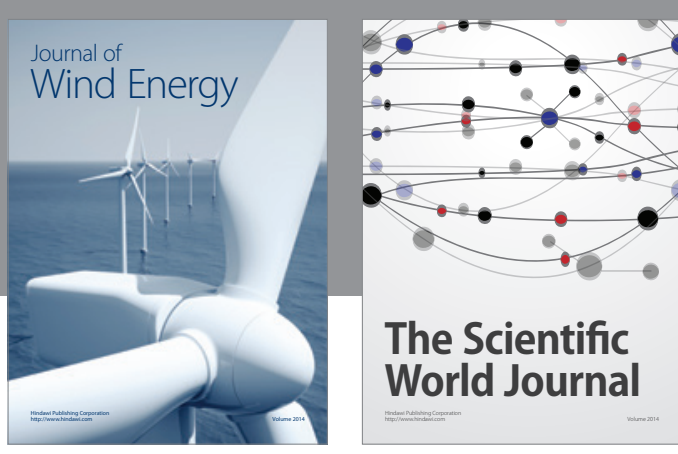

The Scientific World Journal
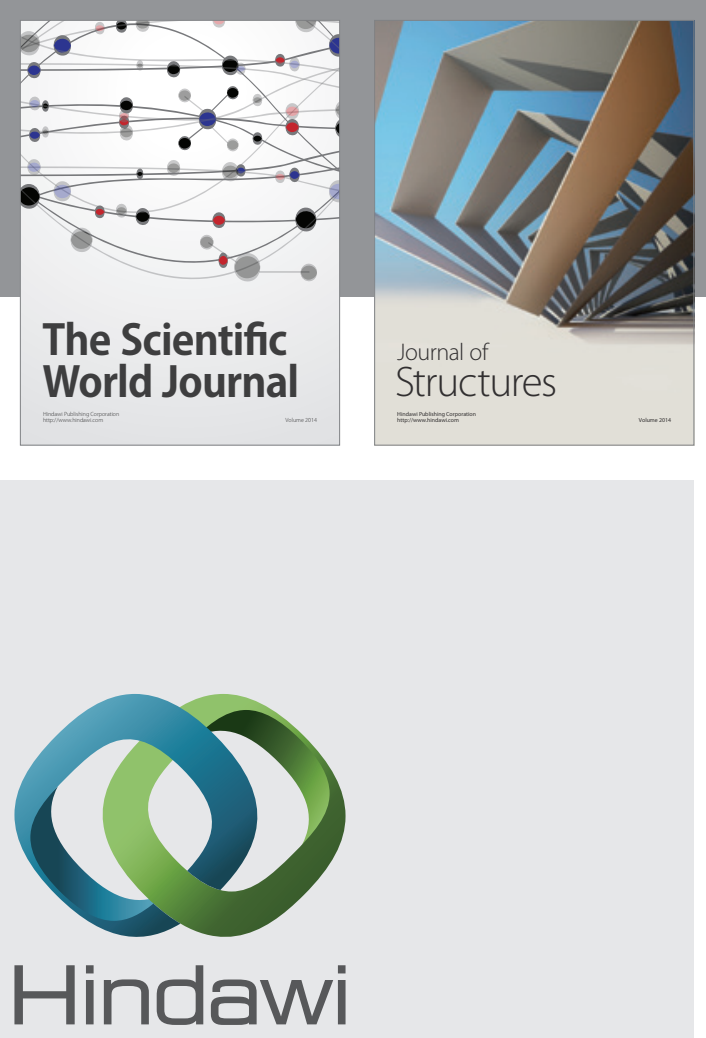

Submit your manuscripts at

http://www.hindawi.com
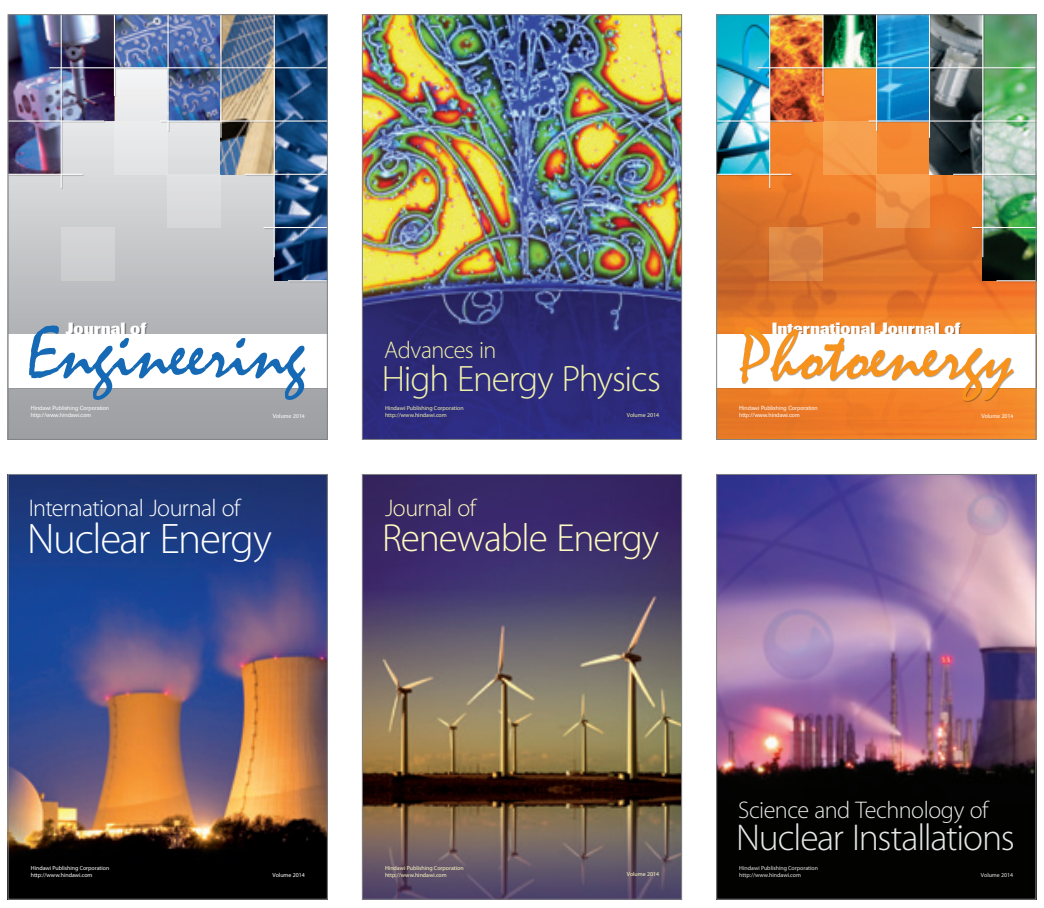
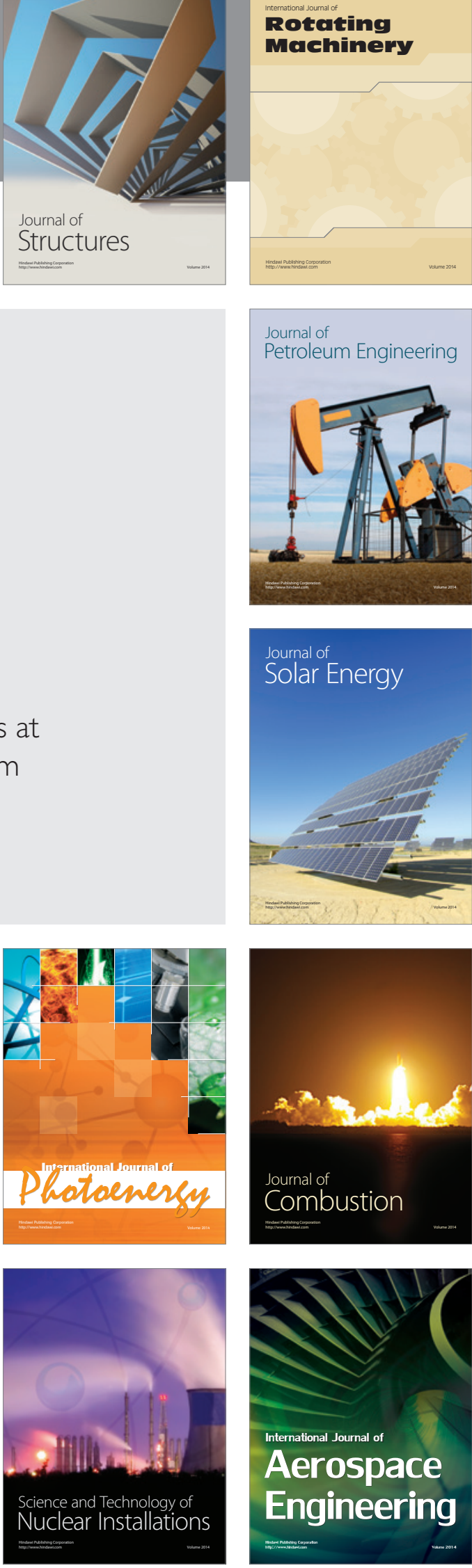